\title{
SMART 2008: Shaking table tests on an asymmetrical reinforced concrete structure and seismic margins assessment
}

\author{
Benjamin Richard ${ }^{\mathrm{a}, *}$, Paolo Martinelli ${ }^{\mathrm{a}, 1}$, François Voldoire ${ }^{\mathrm{b}}$, Mathieu Corus ${ }^{\mathrm{b}}$, Thierry Chaudat ${ }^{\mathrm{a}}$, \\ Salim Abouri ${ }^{\mathrm{c}}$, Nicolas Bonfils ${ }^{\mathrm{c}}$ \\ ${ }^{a}$ CEA, DEN, DANS, DM2S, SEMT, Laboratoire d'Etude de Mécanique Sismique, F-91191 Gif-sur-Yvette, France \\ ${ }^{\mathrm{b}}$ EDF, DRED, Acoustics and Mechanical Analysis Department, 1 avenue du Général de Gaulle, F-92141 Clamart, France \\ ${ }^{\mathrm{c}}$ EDF, SEPTEN, Dynamic and Earthquake Engineering Group, 12-14 avenue Dutriévoz, F-69628 Villeurbanne, France
}

\begin{abstract}
The paper reports the main findings of a series of shaking table tests on a 3-story $1 / 4$-scale reinforced concrete model characterized by strong asymmetry, representative of a nuclear building. The specimen was subjected to 13 bi-directional input ground motions with increasing maximum acceleration from 0.05 to $1.0 \mathrm{~g}$, which induced significant torsion and a nonlinear response. The tests were conducted on the AZALEE shaking table (Saclay, France) as part of a wide research program launched by the French Atomic Energy and Sustainable Energies Commission (CEA), Electricité De France (EDF) and the International Atomic Energy Agency (IAEA), titled, "Seismic design and best-estimate Methods Assessment for Reinforced concrete buildings subjected to Torsion and nonlinear effect (SMART)." Based on the analysis of the test results, the following conclusions were drawn: (a) moderate damage occurred on the specimen (mainly close to the geometric singularities) as revealed by the crack patterns observed at the end of the seismic test sequence; (b) the model responded mainly in the torsional mode; (c) an important specimen stiffness reduction was observed with a shift of the first peak frequency almost equal to 50\%; (d) the seismic margins assessment carried out with two distinct failure criteria (frequency shift and inter-story drift) showed an important specimen robustness for high seismic amplitude as well.
\end{abstract}

\section{Introduction}

The importance of nuclear power plants and the consequences of a nuclear accident require that nuclear power plants be designed to safely withstand the most severe environmental conditions that could reasonably be expected to affect them during their lifetime. This encouraged the nuclear industry to financially support the international scientific community to start ambitious research programs aimed at improving knowledge in several fields of primary importance, and thus, ensuring the safety of nuclear power plants. Within this context, significant improvements have been made in the field of earthquake engineering to better understand the way in which complex reinforced concrete (RC) structures behave when subjected to seismic loading. Moreover, these improvements are oriented to assess design practices and best-estimate methods for structural dynamic response and floor response spectra

\footnotetext{
* Corresponding author.

E-mail address: Benjamin.Richard@cea.fr (B. Richard).

1 Current address: Politecnico di Milano, Department of Civil and Environmental Engineering, Piazza L. da Vinci 32, 20133 Milan, Italy.
}

evaluation, in case of low to far-beyond design seismic motions, and to provide reference data for numerical models validation.

Identified as potentially being able to withstand severe damage, RC shear walls have been extensively studied from the 1970s all over the world. Many research programs aimed at studying the structural behavior of isolated shear walls under static loading have been undertaken [1-11]. The experimental data produced pointed out the high bearing capacity of shear walls when subjected to static loadings. Some experimental campaigns were carried out on RC shear walls, with different reinforcement ratios, under pseudo-dynamic loading conditions, such as within the SAFE (Structure Armées Faiblement Elancées) program, at the Joint Research Center (JRC) operated by the European Commission, located in Ispra, Italy [12], where the available ductility has been confirmed. Additionally, a pronounced decrease of fundamental frequencies has also been observed, which is due to the concrete cracking and the resulting stiffness reduction, at each step of the series of seismic loads with increasing levels (up to 15 times the design level). More recently, in 2010, an experimental program, TESSH (TEsts on Strong SHear wall), was initiated at JRC within the European IRIS project (see [13]) on RC shear walls under static 
reversed cyclic loading conditions, in real size, in order to improve the available ductility and hysteretic models for analysis. A major concern that has not yet been analyzed is the fact that shear walls are generally not used as isolated components but are included in and connected with other components. This may lead to specific structural effects that must be understood. Additional experimental investigations focused on shear walls with end walls [14-19] or framed with beams and columns $[20,21]$ under static loadings.

Structural effects between each component due to the assembly appeared as not negligible. Thus, experimental investigations were carried out on three-dimensional shear walls assembly [22,23], being regular both in-plane and in elevation, which were tested under static conditions. In order to assess the capabilities of shear walls-based structures to withstand seismic loadings, experimental studies where dynamic loadings were considered were carried out. Nevertheless, due to the difficulties of applying a dynamic loading on an RC specimen allowing the description of the inertia force field, experimental data appear rarely in the literature, in particular, when considering such loading conditions applied to a three-dimensional model of a shear walls-based structure. Experiments in which an impulsive loading was considered for analyzing the fundamental dynamic properties of structures are available in the literature [24,25]. The literature also reports a few studies in which a full three-dimensional structural model was subjected to a dynamic load [26-28]. From this brief state-of-the-art review, it can be observed that there is a lack of experimental data regarding shear walls-based structures subjected to dynamic loading.

In order to expand the knowledge about seismic behavior of wall-based structures, the French Atomic Energy and Sustainable Energies Commission (CEA) and Electricité De France (EDF) started a wide research program in 2006, titled "Seismic design and bestestimate Methods Assessment for Reinforced concrete buildings subjected to Torsion and nonlinear effect" (SMART), which has been partially supported by the International Atomic Energy Agency (IAEA). The objectives of the project were: (i) to create reference experimental data to better understand the way in which asymmetric RC wall-based structures behave when subjected to high intensity seismic loadings, (ii) to estimate the seismic margins with respect to the design level, and (iii) to assess the capabilities of numerical methods for seismic assessment of such structures, including beyond the design level by means of best-estimate nonlinear simulations, and for the propagation of uncertainties to feed probabilistic vulnerability assessment studies. The SMART project was split into two parts. The first part consisted in a wide experimental campaign where seismic tests were carried out in 2008 on an asymmetric reduced scale model of an RC wall-based structure by means of the AZALEE shaking table operated by the Nuclear Energy Division (DEN) in the CEA center located in Saclay (France). The second part of the project consisted on an international benchmark aimed at allowing the international earthquake engineering community to express current seismic assessment practices and to share experiences on best-estimate methodologies, in order to provide the engineering community with more efficient tools and guidelines.

The paper aims to expose the experimental contributions that the SMART project has allowed to reach. In particular, the main contribution of the experimental part of the project lies in the fact that the structural model that was tested has an asymmetric inplane shape, leading to high torsional and out-of-plane effects. The seismic testing sequence was chosen in order to allow the assessment of seismic margins, regarding conventional limit states. Lastly, the literature review has clearly shown the lack of available experimental data acquired on three-dimensional structural models when subjected to a full dynamic environment.

This paper is outlined as follows. First, the experimental campaign carried out within the framework of the SMART project is presented. The design principles of the tested RC specimen are described in detail. Then, the specimen geometry is presented as well as the basic mechanical properties of the constitutive materials (concrete and steel). The instrumentation layout and the seismic testing sequence are described. Second, some general experimental observations made during the experimental campaign are described. Third, the main experimental results are shown. The dynamic properties of the RC specimen that were measured right before and after the seismic test sequence through an experimental identification technique are presented. Then, results in terms of floor response spectra and inter-story drifts are shown. Fourth, based on the experimental measurements presented in the previous sections, an estimation of the seismic margins is carried out according to several margin indicators.

\section{Experimental program}

\subsection{Test specimen and material properties}

The RC specimen is a scaled model of a simplified part of a nuclear electrical building. It was prepared to reproduce the geometrical, physical, and dynamic characteristics of part of the real building. Due to the inherent limitations related to the laboratory capacity-no matter the laboratory-some simplifying assumptions must be considered. In case of the AZALEE shaking table, eight $1000 \mathrm{kN}$ actuators are used to apply the seismic load, and specimens having a maximum mass of 100 tons can be tested. The maximum acceleration is $1.0 \mathrm{~g}$, the maximum displacement is $125 \mathrm{~mm}$ in the horizontal directions $(X$ and $Y$ ), and $100 \mathrm{~mm}$ in the vertical direction $(Z)$. In particular, considering the size or mass of the real building and given the load capacity of the AZALEE shaking table [29], the model had to be geometrically reduced to a $1 / 4$ scale. In order to ensure the representativeness of the measurements carried out on a reduced scaled model, similitude laws should be considered. The following conditions must be fulfilled: (i) geometry; (ii) relationship between stresses and strains for all the constitutive materials; (iii) inertia and gravity forces; and (iv) initial and boundary conditions [30,31]. Considering the technical specifications of the AZALEE shaking table (displacement amplitudes, load capacity, etc.), it was possible to ensure the invariance of the stresses and of the accelerations through the scale reduction. The well-known Cauchy-Froude similitude law was therefore chosen in this study. The scaling factors are given in Table 1.

Since the same material properties were chosen for the mockup and for the actual building, in particular the same specific mass, it was necessary to set up additional masses to balance the lack of mass, equal to 3 times the specific mass by the whole volume of the mock-up. It was decided to distribute this additional mass uniformly on the mock-up floors, since this choice has little consequence on their structural role, acting essentially as diaphragms on the RC walls, and because we were not interested in catching the specific flexural behavior of the floors. The total mass of the RC specimen loaded with the additional masses is equal to 44.29 tons. The first slab is loaded with 11.60 tons, second slab with 12.00 tons, and the third slab with 10.25 tons. The mass of the $\mathrm{RC}$ specimen without the additional masses is 10.44 tons.

The RC specimen was designed according to the current French design rules to be considered when dealing with a nuclear building $[32,33]$. The design spectrum that was considered is shown in Fig. 1. It corresponds to an earthquake of magnitude 5.5 at a distance of $10 \mathrm{~km}$ from the rupture plane. The nominal ground acceleration is $0.2 \mathrm{~g}$. Synthetic accelerograms were generated from the design spectrum. The acceleration response spectrum of the selected signal is shown in Fig. 1, where fairly good agreement with the target spectrum can be noted. The selected signal is the 
Table 1

Scale factors of the Cauchy-Froude similitude law $-p$ and $m$ represent the real building (without any scale changes) and the model respectively.

\begin{tabular}{llll}
\hline Parameter & Symbol & Cauchy-Froude's scale factor & Value \\
\hline Length & $L$ & $L_{p} / L_{m}=\lambda$ & 4 \\
Young's modulus & $E$ & $E_{p} / E_{m}=1$ & 1 \\
Specific mass & $\rho$ & $\rho_{p} / \rho_{m}=\lambda^{-1}$ & $1 / 4$ \\
Area & $A$ & $A_{p} / A_{m}=\lambda^{2}$ & 16 \\
Volume & $V$ & $V_{p} / V_{m}=\lambda^{3}$ & 64 \\
Mass & $m$ & $m_{p} / m_{m}=\lambda^{2}$ & 16 \\
Displacement & $d$ & $d_{p} / d_{m}=\lambda$ & 4 \\
Velocity & $v$ & $v_{p} / v_{m}=\lambda^{0.5}$ & 2 \\
Acceleration & $a$ & $a_{p} / a_{m}=1$ & 1 \\
Weight & $W$ & $W_{p} / W_{m}=\lambda^{2}$ & 16 \\
Force & $F$ & $F_{p} / F_{m}=\lambda^{2}$ & 16 \\
Moment & $M$ & $M_{p} / M_{m}=\lambda^{3}$ & 64 \\
Stress & $\sigma$ & $\sigma_{p} / \sigma_{m}=1$ & 1 \\
Strain & $\epsilon$ & $\epsilon_{p} / \epsilon_{m}=1$ & 1 \\
Time & $t$ & $t_{p} / t_{m}=\lambda^{0.5}$ & 2 \\
Frequency & $f$ & $f_{p} / f_{m}=\lambda^{-0.5}$ & $1 / 2$ \\
\hline
\end{tabular}

one with the highest correlation factor with the target spectrum. A detailed description of the generation technique used can be found in [34].

The geometry of the RC specimen was defined in order to fulfill three conditions: (i) the specimen should have an asymmetric shape to experience significant torsional effects during the loading, (ii) the first eigenfrequencies should be in the range $4-10 \mathrm{~Hz}$ to ensure the occurrence of significant damage, and (iii) no significant damage should appear at $50 \%$ of the design level. It is composed of nine structural elements: one foundation, three shear walls with openings, three slabs, three beams and one column. The formwork drawings of the RC specimen are shown in Fig. 2. It is $3.65 \mathrm{~m}$ high and has an in-plane trapezoidal shape. The main shear wall is composed of two shear walls (SW2 and SW3) and is $3.10 \mathrm{~m}$ long. The medium shear wall (SW1) is $2.55 \mathrm{~m}$ long while the last shear wall (SW4) is $1.05 \mathrm{~m}$ long. All the shear walls and the slabs are $0.10 \mathrm{~m}$ thick. The RC beams, located under the lower face of the floors, are $1.45 \mathrm{~m}$ long with a rectangular cross-section of $0.325 \mathrm{~m} \times 0.15 \mathrm{~m}$. The RC column is $3.80 \mathrm{~m}$ high and has a rectangular cross-section of $0.20 \mathrm{~m} \times 0.20 \mathrm{~m}$. Lastly, the shear wall foundation is made of a continuous RC footing that is $0.38 \mathrm{~m}$ wide and $0.15 \mathrm{~m}$ high. The footing is anchored on a $0.02 \mathrm{~m}$ thick steel plate that is linked with the shaking table upper plate by means of appropriate screws and nuts. The RC column is anchored on a $0.62 \mathrm{~m} \times 0.62 \mathrm{~m} \times 0.02 \mathrm{~m}$ steel plate. The steel reinforcing ratio is

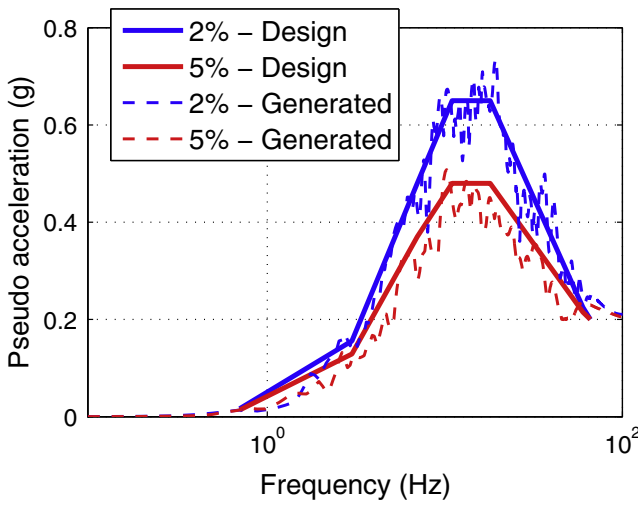

Fig. 1. Comparison between design spectrum and response spectra for the generated input ground motions - $2 \%$ and $5 \%$ damping - earthquake magnitude equal to 5.5 . close to $2.3 \%$ for the shear walls and $2 \%$ for the slabs. A detailed presentation of the steel reinforcing drawing can be found in [35].

The target mechanical properties of the constitutive materials (concrete and steel reinforcements) used for the RC specimen have been defined according to the current engineering design rules used in the French nuclear industry [33]. In order to have the necessary data to develop numerical models, characterization tests were carried out. In particular, concrete strength was measured by means of compressive tests carried out on cylindrical specimens $(160 \mathrm{~mm} \times 320 \mathrm{~mm})$ and Brazilian tests, respectively. Due to the fact that the RC specimen was built in seven different casts, concrete was characterized in several areas not only at 28 days but also at the beginning of the seismic tests. Twelve samples were tested per cast. The experimental results are reported in Table 2.

The steel reinforcements put in the RC specimen had five different diameters. Due to the scale reduction, diameters ranged from $3 \mathrm{~mm}$ up to $10 \mathrm{~mm}$. It is important to note that no provider has been able to provide ribbed bars for all diameters. The steel bars with a diameter of 3 and $4 \mathrm{~mm}$ are smooth, whereas the bars with other diameters $(6,8$ and $10 \mathrm{~mm})$ are ribbed. Characterization tests were carried out according to the current engineering practice [36]. The main results are shown in Table 3.

\subsection{Sensors layout}

The measurement points were defined in order to capture the overall structural response of the specimen during the seismic loading as well as the local effects such as steel yielding. A total of 264 acquisition channels were used, 230 were dedicated to the RC specimen and 34 were dedicated to the shaking table. Regarding the channels devoted to the specimen, accelerometers, linear variable differential transformer (LVDT) and strain gauges were adopted. The location of the main measurement points (except for strain gauges) is shown in Fig. 3. Displacement time histories were measured in both $X$ and $Y$ directions at the four corners of each slab with respect to an external rigid frame fixed out of the shaking table (approximately $75 \mathrm{~cm}$ far from the shaking table sides). In addition, displacement time histories were also measured in the $Z$ direction not only between each slab at point $E$ but also between the points $A, B, C$ and $D$ located at the third floor, and the corresponding points located at the foundation level. Lastly, LVDTs were also used to monitor the relative displacement time histories at the interface between the specimen and the shaking table upper plate. A detailed description of the sensors arrangement is available in [35]. Among the channels dedicated to the shaking table, accelerometers were put at its upper plate center to monitor the accelerations according to both horizontal ( $X$ and $Y$ ) and vertical $(Z)$ directions. In addition, the so-called degrees of freedom (DOFs) automatically computed by the shaking table controller were also recorded in order to have global information related to the spatial position of the tested system (shaking table and RC specimen). This information can be used as loading input to feed the numerical models.

\subsection{Test loading protocol}

The seismic loading sequence is summarized in Table 4. The loading protocol is composed of 21 biaxial seismic runs in the horizontal directions $(X$ and $Y$ ). The input signals used during the runs $\# 1$, \#2, \#13, \#14, \#16, \#17, \#19 and \#20 were white noise signals with a peak ground acceleration (PGA) level limited to $0.05 \mathrm{~g}$. They were dedicated to the identification of the modal properties of the RC specimen. In runs \#3 and \#4, seismic signals coming from actual records were used with a PGA level equal to $0.05 \mathrm{~g}$. The objective of these two preliminary seismic runs was to create an initial light damage state, as can be observed in existing RC 

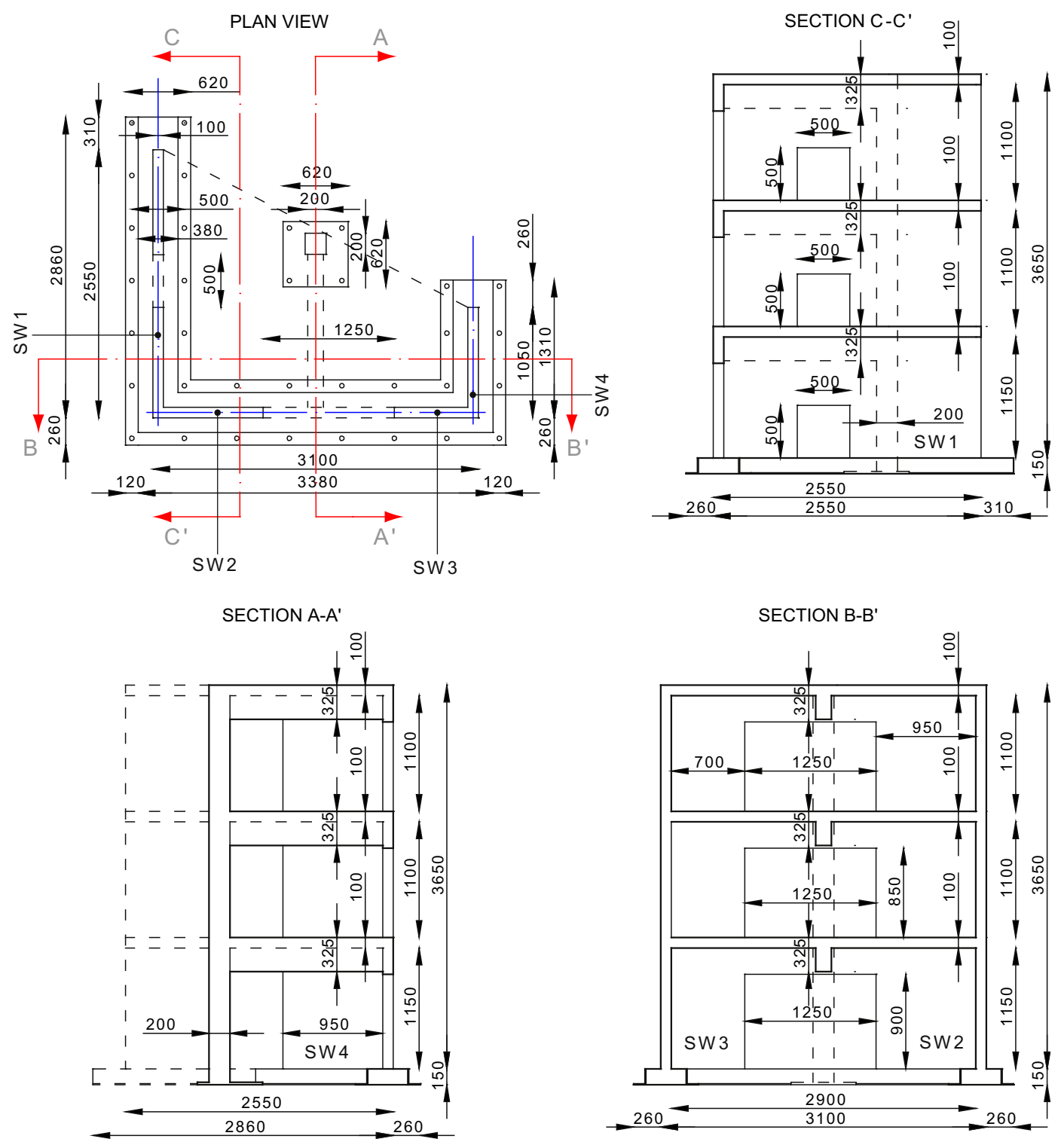

Fig. 2. Formwork drawings of the RC specimen - dimensions in mm.

Table 2

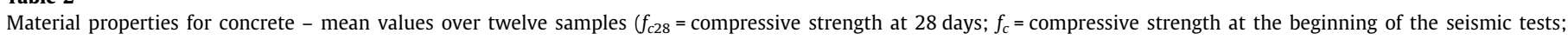
$f_{\mathrm{ct}}=$ tensile strength at the beginning of the seismic tests; $E_{\mathrm{ct}}=$ Tangent Young's modulus; $E_{\mathrm{cs}}=$ Secant Young's modulus).

\begin{tabular}{|c|c|c|c|c|c|}
\hline Structural component & $f_{c 28}(\mathrm{MPa})$ & $f_{c}(\mathrm{MPa})$ & $f_{\mathrm{ct}}(\mathrm{MPa})$ & $E_{\mathrm{ct}}(\mathrm{GPa})$ & $E_{\mathrm{cs}}(\mathrm{GPa})$ \\
\hline Foundation & 35 & 50 & 2.9 & 31 & 30 \\
\hline Shear wall and column - 1st level & 32 & 44 & 3.0 & 30 & 29 \\
\hline Slab and beam - 1st level & 28 & 40 & 2.6 & 29 & 26 \\
\hline Shear wall and column - 2nd level & 29 & 37 & 2.6 & 26 & 25 \\
\hline Slab and beam - 2nd level & 36 & 43 & 2.9 & 31 & 30 \\
\hline Shear wall and column - 3rd level & 30 & 40 & 2.6 & 33 & 30 \\
\hline Slab and beam - 3rd level & 32 & 37 & 2.5 & 29 & 28 \\
\hline
\end{tabular}

structures. In runs \#5 to \#12, and runs \#15, \#18 and \#21, biaxial seismic input motions were applied to the RC specimen. These input signals were synthetic; they were generated from the design spectrum. The PGA level was progressively increased in order to estimate the seismic margins of the RC specimen with respect to the design level. It is important to note that runs in which white noise signals were considered are not included in Table 4.
In addition, the PGA related to the prescribed input signal is referred to as "target PGA," and the one related to the measured signal on the upper plate of the shaking table is referred to as "realized PGA." The differences between both types of PGA can be explained by some gaps in the control system. Nevertheless, it is important to remember that the PGA is a high frequency indicator; it does not represent the whole frequency range of the input 
Table 3

Material properties for steel - mean values over three samples.

\begin{tabular}{|c|c|c|c|c|c|c|}
\hline $\begin{array}{l}\text { Steel } \\
\text { diameter } \\
(\mathrm{mm})\end{array}$ & $\begin{array}{l}\text { Young's } \\
\text { modulus } \\
(\mathrm{GPa})\end{array}$ & $\begin{array}{l}\text { Yield } \\
\text { strength } \\
(\mathrm{MPa})\end{array}$ & $\begin{array}{l}\text { Ratio between the ultimate strength } \\
\text { and the yield strength }\end{array}$ & $\begin{array}{l}\text { Strain corresponding to the } \\
\text { yield strength }\left(\times 10^{-6}\right)\end{array}$ & $\begin{array}{l}\text { Strain corresponding to the } \\
\text { ultimate strength (\%) }\end{array}$ & Steel type \\
\hline 10 & 205 & 630 & 1.04 & 3.073 & 2.07 & Ribbed \\
\hline 8 & 180 & 560 & 1.04 & 3.111 & 4.33 & Ribbed \\
\hline 6 & 180 & 559 & 1.04 & 3.105 & 5.80 & Ribbed \\
\hline 4 & 184 & 559 & 1.07 & 3.040 & 4.10 & Smooth \\
\hline 3 & 205 & 776 & 1.03 & 3.785 & 3.94 & Smooth \\
\hline
\end{tabular}

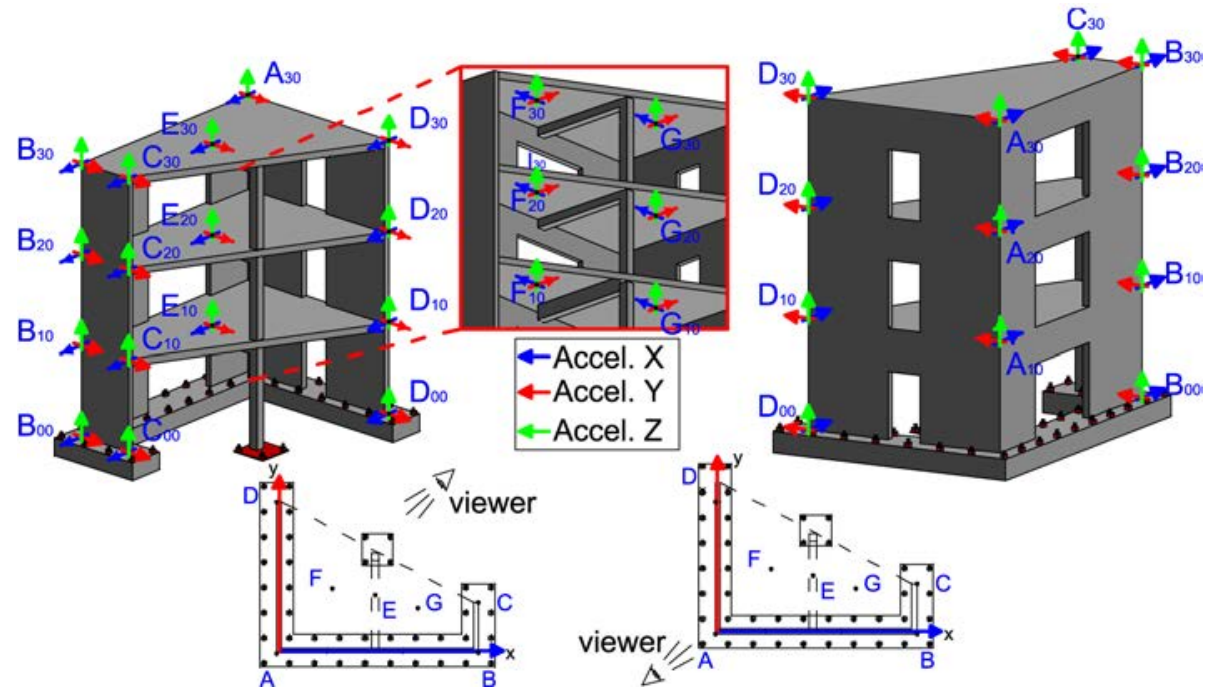

Fig. 3. Main measurement points.

Table 4

Seismic loading sequence - runs \#5 and \#7 (in bold in the table) correspond to the half design and design levels, respectively.

\begin{tabular}{|c|c|c|c|c|c|c|c|}
\hline Run \# & Target PGA (g) & Measured PGA in $X$ direction (g) & Measured PGA in $Y$ direction $(\mathrm{g})$ & Maximum PGA (g) & Mean PGA (g) & Type of signal & Duration (s) \\
\hline 3 & 0.05 & 0.09 & 0.03 & 0.09 & 0.06 & Natural & 15 \\
\hline 4 & 0.05 & 0.08 & 0.05 & 0.08 & 0.065 & Natural & 15 \\
\hline 5 & 0.10 & 0.19 & 0.15 & 0.19 & 0.17 & Synthetic & 15 \\
\hline 6 & 0.15 & 0.20 & 0.24 & 0.24 & 0.22 & Synthetic & 25 \\
\hline 7 & 0.20 & 0.19 & 0.20 & 0.20 & 0.195 & Synthetic & 25 \\
\hline 8 & 0.30 & 0.23 & 0.32 & 0.32 & 0.275 & Synthetic & 25 \\
\hline 9 & 0.40 & 0.33 & 0.35 & 0.35 & 0.34 & Synthetic & 25 \\
\hline 10 & 0.50 & 0.41 & 0.55 & 0.55 & 0.48 & Synthetic & 25 \\
\hline 11 & 0.60 & 0.41 & 0.56 & 0.56 & 0.485 & Synthetic & 25 \\
\hline 12 & 0.70 & 0.53 & 0.67 & 0.67 & 0.6 & Synthetic & 25 \\
\hline 15 & 0.80 & 0.58 & 0.77 & 0.77 & 0.675 & Synthetic & 25 \\
\hline 18 & 0.90 & 0.70 & 1.06 & 1.06 & 0.88 & Synthetic & 25 \\
\hline 21 & 1.00 & 0.75 & 1.13 & 1.13 & 0.94 & Synthetic & 25 \\
\hline
\end{tabular}

signal. The target response spectrum is in accordance with the prescribed one in the frequency range $0-30 \mathrm{~Hz}$, which is the classical range considered for AZALEE-like shaking tables.

\section{Experimental observations}

Before reaching run \#8, in which the maximum PGA in both $X$ and $Y$ directions was equal to $0.32 \mathrm{~g}$ (Table 4), no significant damage was observed on the shear walls, the beams or the slabs. The first cracks appeared on the foundation during run \#8, at the end of SW1, SW2 and SW4. All cracks were along the width of the foundation. It is important to note that for seismic runs with higher intensity, no other cracks were initiated; only cracks created during run \#8 continued to propagate in a limited way. The position of the main cracks observed in the foundation is shown in Fig. 4. This observation led to assume that the foundation exhibited a non-negligible flexibility during the seismic loading, which induced the development of the first cracks.

From runs \#9 to \#12, only limited smeared cracks were observed in the areas characterized by a geometrical irregularity such as the ones located near the opening (see Fig. 5a) or the lintels (see Fig. 5b) between wall SW1 and SW2.

During run \#15, horizontal and diagonal cracks appeared in the shear walls along the height, and between the foundation level and the first floor. From runs \#18 to \#21, cracks kept propagating mainly in the lintels; no significant cracking initiation was monitored. The RC slabs were damaged during this part of the experimental seismic sequence, as shown in Fig. 6a. It seems that the slabs worked by bending more than as a membrane. The most damaged area of the RC specimen was the shear wall SW4, as shown in Fig. 6b. This observation is consistent with the fact that this shear wall is located the farthest from the torsion center of 


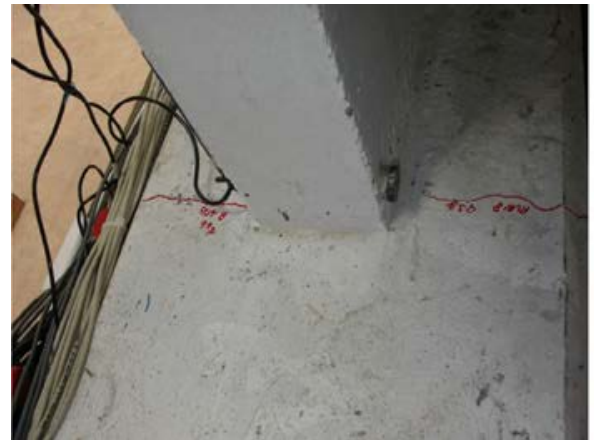

(a) Connection between SW1 and the foundation.

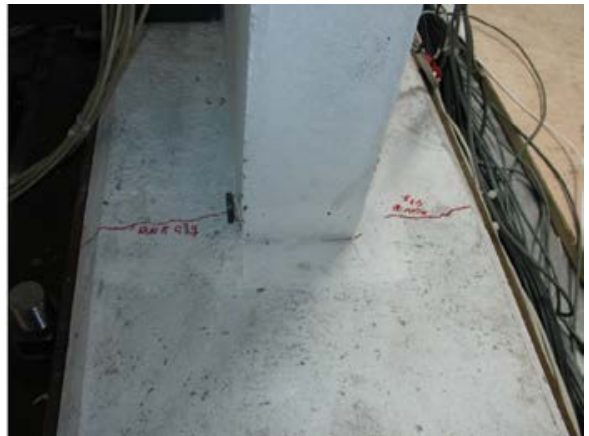

(b) Connection between SW2 and the foundation.

Fig. 4. Cracking pattern at the foundation level - run \#8.

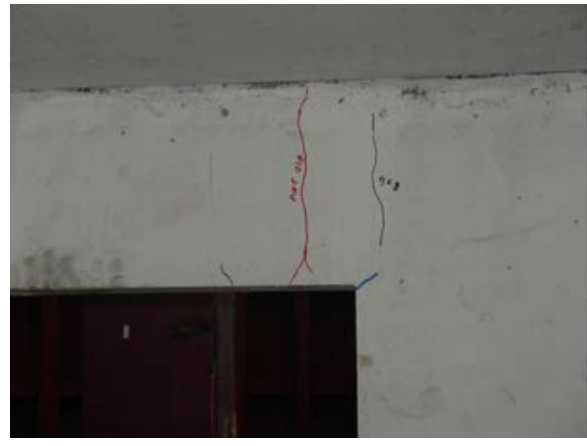

(a) Cracks close to the opening of the $1^{\text {st }}$ floor - shear wall SW2.

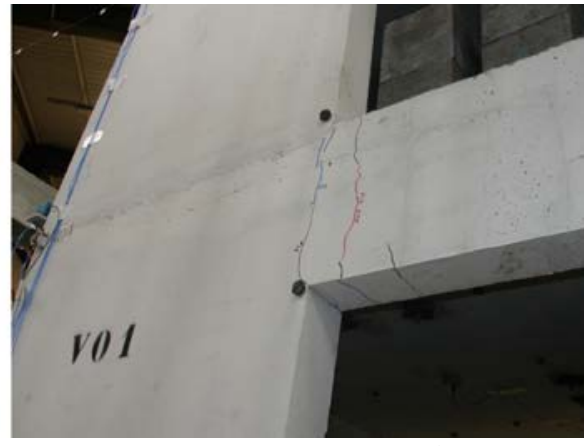

(b) Cracks in the lintels at the $2^{\text {nd }}$ floor shear wall SW1.

Fig. 5. Cracking pattern - run \#11.

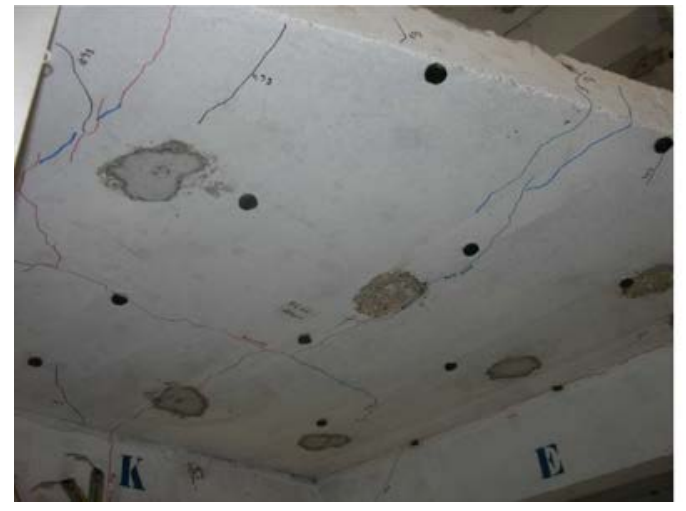

(a) Most damaged slab located at the $1^{\text {st }}$ floor

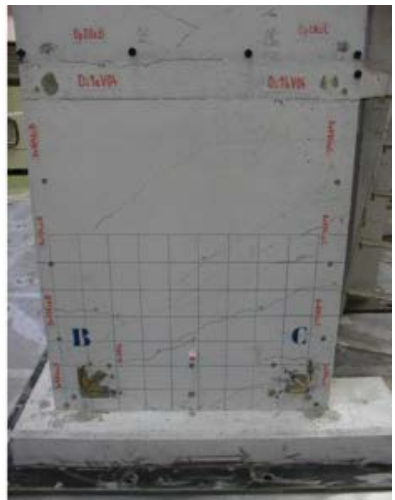

(b) Shear wall SW4.

Fig. 6. Cracking patterns - run \#21.

the RC specimen and consequently, it is subjected to the highest loads. At the end of the seismic sequence, a controlled damage was observed according to the European macroseismic scale updated in 1998 (EMS98) [37].

\section{Experimental results and discussion}

\subsection{Natural vibration properties}

\subsubsection{Description of the methodology}

This section aims at exposing the driving ideas of the modal identification method used; an in-depth presentation can be found in $[38,39]$. The specimen under study is instrumented with accelerometers. The basic idea is in prescribing a specific input signal to the specimen, and then, to measure the structural responses. Resulting measurements are post-processed to extract the modal properties (eigenfrequencies, modal damping and mode shapes) for each mode of interest. The underlying assumptions are presented in the following paragraphs.

The behavior of the structure is assumed to be linear elastic. Under this assumption, the dynamic system can be represented in the frequency domain by a second order model as follows:

$\left(-\omega^{2} M+j \omega D_{v}+K\right) q(\omega)=f(\omega)$

where $\omega$ is the angular frequency, $M$ the mass matrix, $D_{v}$ the viscous damping matrix, $j$ the imaginary unit such that $j^{2}=-1, K$ the 
stiffness matrix, $q$ the generalized degrees of freedom characterizing the displacement response of the dynamic system and $f$ the external loading expressed in the frequency domain. Hence, the transfer function $H_{i j}$ between an input located on the sensor $i$ (force) and the output of the sensor $j$ (displacement) is given by a second order model. It is assumed that the transfer function $H_{i j}$ is expressed as a rational fraction of numerator $P_{i j}$ and denominator $Q_{i j}$, of order $r$ and $r+2$, respectively. More precisely, the transfer function is approximated by the following expression:

$H_{i j}(\omega)=\frac{P_{i j}(\omega)}{Q_{i j}(\omega)}=\frac{\sum_{k=0}^{r} p_{k} \omega^{k}}{\sum_{k=0}^{r+2} q_{k} \omega^{k}}$

where $r$ is an even integer, $p_{k}$ and $q_{k}$ are the complex coefficients of the polynomial terms $P_{i j}$ and $Q_{i j}$ that need to be identified. For the frequency ranges of interest, in the neighborhood of each mode, the linear system giving coefficients of $P_{i j}$ and $Q_{i j}$ is solved in the least square sense for increasing values of $r$. Eigenfrequencies and related modal damping are given by the stable roots of $Q_{i j}$.

Other techniques $[40,41]$ benefit from the rational fractions properties in order to improve both the computational time of the whole analysis and the accuracy in case of close modes. The dynamic identification of the system was carried out right before and after the seismic test sequence in order to follow the evolution of the modal properties due to damage.

\subsubsection{Experimental design}

The accuracy of the identification technique is mainly dependent on the relevance of the experimental design to be implemented on the RC specimen. A preliminary numerical modal analysis aimed at (i) estimating the range of the eigenfrequencies to be identified, (ii) selecting the areas of interest, and (iii) defining a point to apply the load to the RC specimen, has been carried out. Within the framework of the SMART 2008 experimental campaign, several operational modal analyses under different boundary and structural conditions were carried out. The RC analyzed specimen conditions are the following: free-free condition (RC specimen pulled out); a fixed base condition (RC specimen anchored to the steel plate on which it was built); the RC specimen connected to the shaking table's upper plate with and without additional masses on the slabs; and last, the RC specimen connected with the shaking table's upper plate with additional masses after being subjected to the whole seismic test sequences. For the sake of brevity, an option has been made in this paper to show a subset of the results and only the ones used as starting and final points for the SMART 2008 International Benchmark participants are considered [42]. The results from the modal identification carried out right before and right after the seismic test sequence are shown and discussed. The whole experimental analysis is available in [43].

The position of the sensors has been defined not only to allow a correct identification of the structure movements but also to follow the global shape of the specimen geometry, making the subsequent analyses easier. The sensors mesh, made of accelerometers, is shown in Fig. 7. One hundred sixty-four measurement points were considered. At each point, accelerometers in the three directions $(X, Y$ and $Z$ ) have been placed. Forty sensors were placed on each shear wall, ten on each slab and four additional sensors on the RC column. Thirty sensors were dedicated to the connection between the shaking table's upper plate and the bottom of the foundation. The choice of the point for impacting the RC specimen comes in a natural way since a strong coupling between the modal responses in $X$ and $Y$ directions appeared. It was decided that a point located at the junction between the first slab and the RC column (plain red point shown in Fig. 7a) would be chosen. It was expected that the RC specimen would mainly exhibit overall modes since the impacted point has a high apparent stiffness.
The RC specimen was excited in the plane containing the first slab by an impact hammer blow.

\subsubsection{Identification before the seismic test sequence}

In this section, the modal properties of the RC specimen anchored on the shaking table's upper plate with additional masses placed on the slabs are presented. The first three mode shapes are shown in Fig. 8 and the corresponding eigenfrequencies and modal damping ratios are reported in Table 5. In the case of the first mode, bending around the $Y$ direction is preponderant, whereas in the case of the second mode, bending becomes preponderant around the $X$ direction. However, due to the irregularity of the RC specimen, torsional effects in connection with bending appear. In the case of the third mode, torsional effects are the most important. Furthermore, the small values of the modal damping ratios identified by operational modal analysis may be explained by the fact that we consider a bare building without any non-structural element, known to produce additional damping. However, further work is needed to explain more thoroughly the occurrence of these small values.

\subsubsection{Identification after the seismic test sequence}

The RC specimen anchored on the shaking table upper plate with additional masses put on the slabs has also been subjected to an operational modal analysis after the whole seismic test sequence. The modal properties identified are presented in this section. The first three mode shapes are shown in Fig. 9; the corresponding eigenfrequencies and modal damping ratios are listed in Table 6 . One can notice that the mode shapes were not modified by the seismic test sequence, and they remain close to the ones identified at the beginning of the test procedure.

\subsubsection{Discussion}

The results from the operational modal analysis shown in the previous sections allowed for a characterization of both the initial and the final dynamic conditions of the RC specimen. A first key point of interest is that the seismic loading did not affect the mode shapes, as can be appreciated when comparing Figs. 8 and 9. Indeed, no particular modal energy transfer from a given mode to another is observed. The order of the various mode shapes is preserved, despite cracking developed in the RC specimen. A second key point is the significant decrease of the first eigenfrequency, highlighting the fact that the overall stiffness has been decreased due to crack propagation. The first eigenfrequency is decreased by a factor almost equal to 1.39 (almost $-28 \%$ ). The second and third eigenfrequencies are not as significantly affected as the first one. This can be connected with the failure mechanism that mainly affects the first mode. A third key point is related to the modal damping variations between the initial and final structural states. In the undamaged conditions, it can be pointed out that modal damping ratios are almost the same for all the modes. In particular they are equal to $2 \%$, which is a classical value used in the engineering practices $[33,44]$ when it is expected that an RC specimen exhibits nonlinearities. For the damaged condition case, the damping ratio related to the first mode increases drastically, whereas the ones related to the second and third modes slightly decrease. This is in accordance with the variations of the eigenfrequencies described previously. Indeed, if a given eigenfrequency decreases, it means damage has appeared, leading to an increase in the dissipated energy in natural vibrations conditions. These results were confirmed using other loading conditions, by means of white noise ground motion combined with the half power bandwidth method; nevertheless, as boundary conditions are a little bit different since shaking table actuators are active in that case, modal frequencies values differ from hammer shock tests. In fact, hammer shock tests carried out right before the seismic test sequence led to modal damping ratios equal to $1.3 \%$ for the first mode and $1.5 \%$ for the 


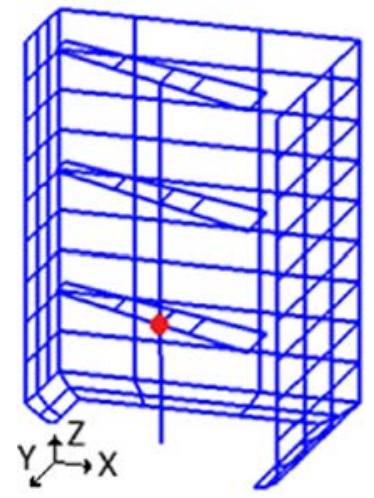

(a) Global sensors mesh - impacted point plotted in red.

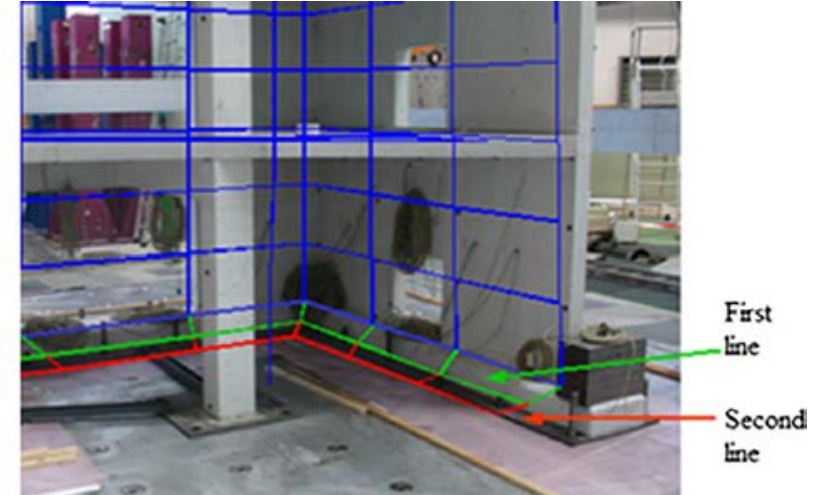

(b) Detail of the sensors mesh - first and second lines plotted in green and red respectively.

Fig. 7. Experimental design for operational modal identification [43].

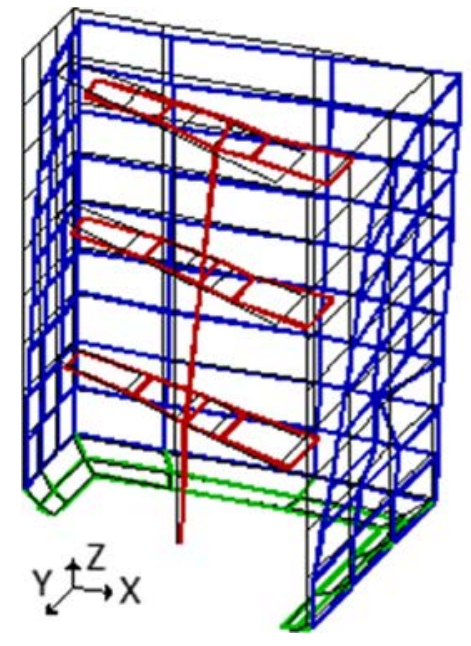

(a) $1^{\text {st }}$ modeshape

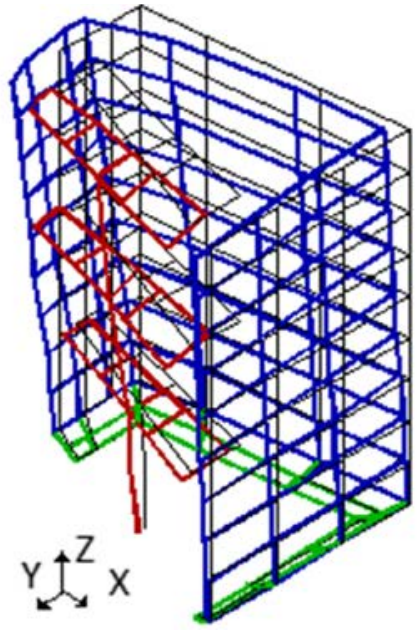

(b) $2^{\text {nd }}$ modeshape

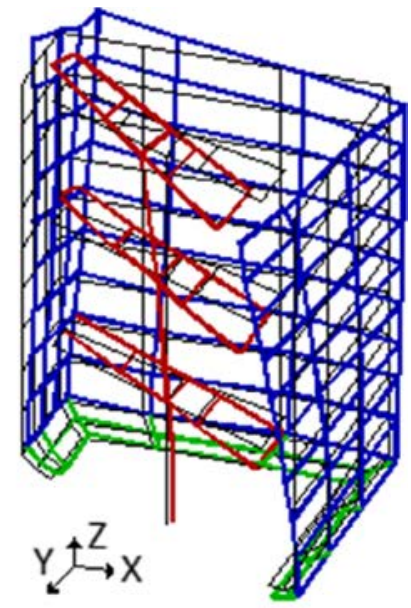

(c) $3^{\text {rd }}$ modeshape

Fig. 8. First three modeshapes of the RC specimen anchored on the shaking table's upper plate with the loaded slabs - before the seismic test sequence [43].

Table 5

Modal properties of the RC specimen anchored on the shaking table's upper plate with additional masses put on the slabs - before the seismic test sequence.

\begin{tabular}{llll}
\hline $\begin{array}{l}\text { Mode } \\
\text { number }\end{array}$ & $\begin{array}{l}\text { Eigenfrequency } \\
(\mathrm{Hz})\end{array}$ & $\begin{array}{l}\text { Modal damping } \\
\text { ratio }(\%)\end{array}$ & Observation \\
\hline 1 & 6.8 & 1.8 & $\begin{array}{l}\text { Bending around } Y \\
\text { direction } \\
\text { Bending around } X \\
\text { direction } \\
\text { Torsion around } Z \\
\text { direction }\end{array}$ \\
\hline
\end{tabular}

second mode. Similar tests were conducted right after the seismic test sequence and led to higher values of the modal damping ratios, which are equal to $4.1 \%$ for the first mode and $6.5 \%$ for the second mode.

\subsection{Acceleration response}

In order to study the acceleration response of the RC specimen during the seismic test sequence, the acceleration response spectra for $5 \%$ damping were computed at point $D$ located on the third floor of the structure, in both $X$ and $Y$ directions. This measurement point was chosen because it exhibited the highest acceleration values, since it is the farthest point from the mock-up shear center. The results are shown in Fig. 10a and b. It is worth noting that no signal processing technique was applied to the experimental measurements.

Two main acceleration response peaks appeared for all seismic runs in both $X$ and $Y$ directions. The asymmetric response was due to the geometrical asymmetry of the RC specimen. This observation is consistent with the first two mode shapes identified in Section 4.1. For run \#6 (PGA equal to $0.15 \mathrm{~g}$ ), the frequencies corresponding to the first and the second peaks were around $7 \mathrm{~Hz}$ and $12 \mathrm{~Hz}$, respectively. These peak frequencies were close to the two first eigenfrequencies of the undamaged specimen, as presented in Section 4.1. As an indicator of structural changes, it is interesting to note that both frequency peaks moved toward the low frequencies range. This indicates that the RC specimen exhibited a decrease of the structural stiffness. This frequency decrease can be used for the seismic margin indicators evaluation; this aspect is discussed in Section 5. 


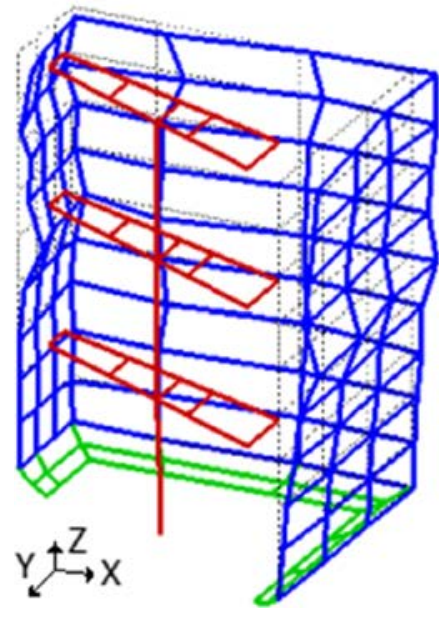

(a) $1^{\text {st }}$ modeshape

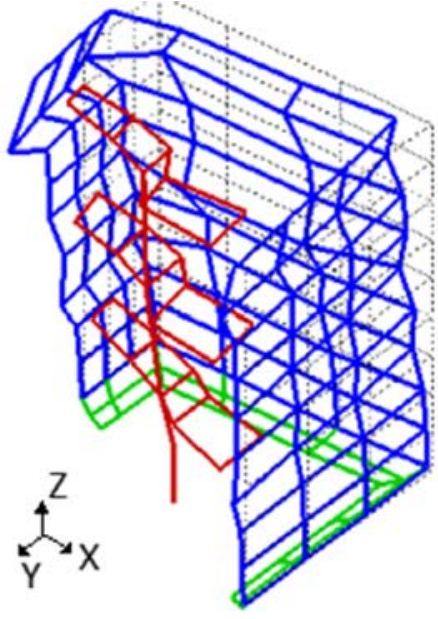

(b) $2^{\text {nd }}$ modeshape

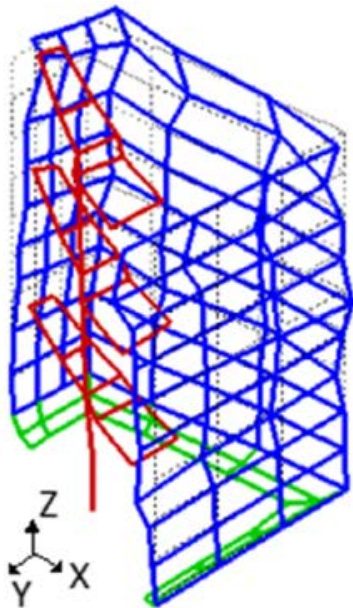

(c) $3^{\text {rd }}$ modeshape

Fig. 9. First three modeshapes of the RC specimen anchored on the shaking table's upper plate with the loaded slabs - after the seismic test sequence [43].

Table 6

Modal properties of the RC specimen anchored on the shaking table's upper plate with additional masses put on the slabs - after the seismic test sequence.

\begin{tabular}{llll}
\hline $\begin{array}{l}\text { Mode } \\
\text { number }\end{array}$ & $\begin{array}{l}\text { Eigenfrequency } \\
(\mathrm{Hz})\end{array}$ & $\begin{array}{l}\text { Modal damping } \\
\text { ratio }(\%)\end{array}$ & Observation \\
\hline 1 & 4.9 & 3.1 & $\begin{array}{l}\text { Bending around } Y \\
\text { direction } \\
\text { Bending around } X \\
\text { direction } \\
\text { Torsion around } Z \\
\text { direction }\end{array}$ \\
\hline
\end{tabular}

With the aim to analyze the effect of nonlinearities on the overall behavior of the RC specimen when subjected to the seismic sequence, the spatial distribution of the zero period acceleration (ZPA) on the specimen floors was studied. Indeed, this quantity is of primary importance particularly in the nuclear industry when equipment or secondary structures must be designed, or when their seismic assessment should be carried out $[45,46]$. In addition, due to the fact that the equipment exhibits a high stiffness, they are often designed in the high frequency domain; the ZPA is therefore considered for the determination of the shear load acting on the anchorage area. The ZPA results for increasing levels of PGA are shown in Fig. 11 for both $X$ and $Y$ directions. It is interesting to observe the different trends that appear in both directions. Along the $X$ direction, which is almost directly connected at this point $\mathrm{D}$ with the torsional motion of the structure, the ZPAs seem to be spatially distributed in a linear way for all seismic runs having a PGA lower than 0.5-0.6 g; for higher PGA seismic runs, a nonlinear distribution appears over the floors. This may be explained by the existence of a structural modification of the RC specimen. Indeed, damage propagated pretty quickly from run \#11. As a consequence, induced anisotropy was created in the RC specimen due to cracking, which appeared at the wall/slab connection. This may explain the discrepancy observed. In particular, the ZPAs increased in the case of the first floor and decreased in the case of the third floor. On the contrary, in the case of the second floor, the variation of the ZPAs was not monotonic. One can observe an increasing phase (up to a PGA around $0.7 \mathrm{~g}$ ) followed by a decreasing phase. This evolution seems to be the result of a combination of the trends observed for the first and the third floor. On the other hand, a totally different trend appeared in the $Y$ direction. In this case, the ZPAs were distributed in a linear way for almost all seismic runs. The effect of the structural modification that might be responsible for the asymmetric distribution of the ZPAs in the $X$ direction did not have any influence when looking at the results in the $Y$ direction. This does not seem surprising due to the asymmetrical shape of the RC specimen.

\subsection{Displacement response}

In order to appreciate the kinematic of the RC specimen during the seismic test sequence, the displacement responses are

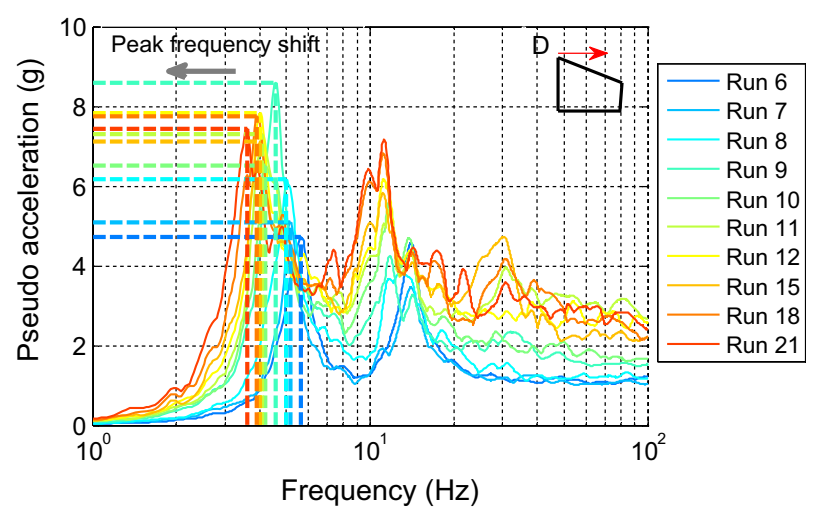

(a) $\mathrm{X}$ direction

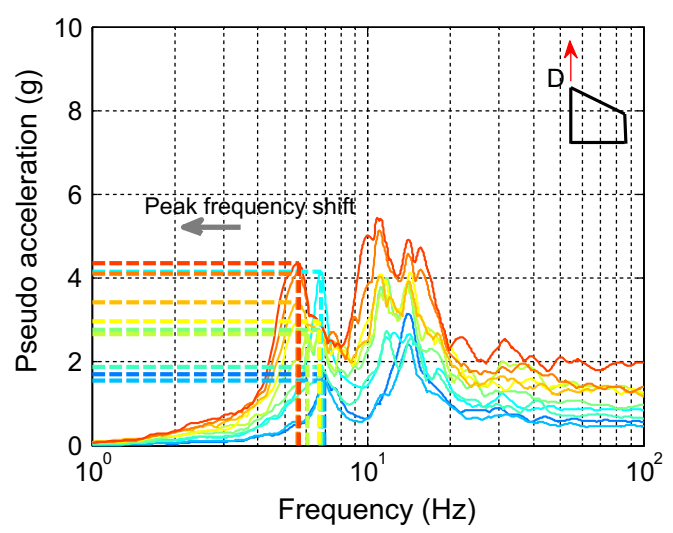

(b) Y direction

Fig. 10. Acceleration response spectra for $5 \%$ damping - point D - 3rd floor. 


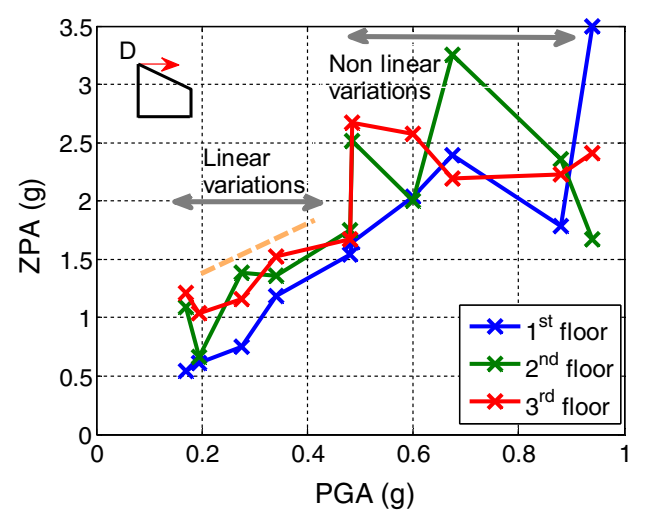

(a) $\mathrm{X}$ direction

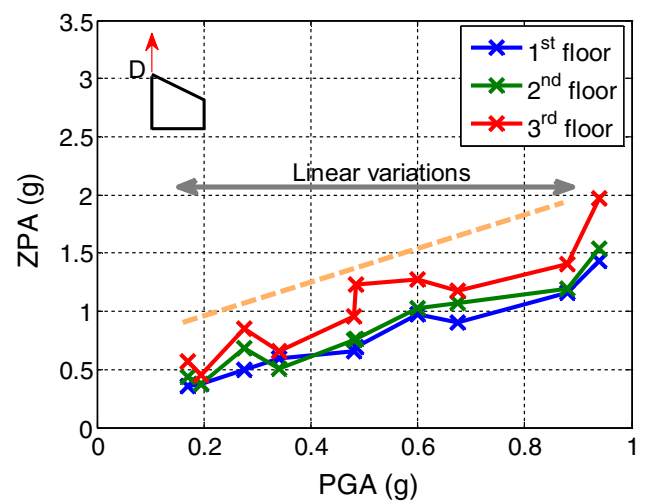

(b) $\mathrm{Y}$ direction

Fig. 11. Spatial distribution of the ZPAs computed at point D over the floors of the RC specimen versus the PGA of each input ground motion.

analyzed in this section. First, one is focused on the maximum relative displacements at points $\mathrm{A}$ and $\mathrm{D}$ in both $X$ and $Y$ directions. The maximum values were determined for the three floors by computing the difference between the absolute displacements measured at the considered point (A or D) and the absolute displacement of the shaking table's upper plate. Therefore, the reference is the shaking table's upper plate, or in other words, the bottom face of the footings. The results are shown in Figs. 12 and 13 . Similarly to the acceleration time histories measurements presented in the previous section, no signal processing technique was applied to the displacement time histories monitored during the experimental campaign. It is important to note that for the values of the relative displacement shown on the aforementioned figures, the same time was considered. The time instant was selected as the instant corresponding to the maximum displacement of the top floor. Looking at Fig. 12, it is interesting to note the difference between the magnitudes of the relative displacement computed at points $A$ and $D$. For point $A$, the maximum relative displacement is around $10 \mathrm{~mm}$, while for point $\mathrm{D}$, it is around $7.5 \mathrm{~mm}$. This result once again points out the fact that the RC specimen was highly subjected to the torsional effects when loaded. In addition, looking at Fig. 13, small differences appear when considering the results obtained at the same points but in the $Y$ direction.

With the aim to better clarify the overall movement of the RC specimen, representation of the relative displacement fields at points $\mathrm{A}, \mathrm{B}, \mathrm{C}$ and $\mathrm{D}$ located on the third floor, was carried out for all the seismic runs. The results are shown in Fig. 14. It is worth mentioning that a magnification factor equal to 40,000 has been considered to allow a clear representation. Despite the fact that these results remain intrinsically qualitative, since they aim at showing the kinematic of the RC specimen during the seismic test sequence without giving specific quantitative information, they corroborate the observations made previously. Indeed, it clearly appears that the displacement fields measured at each corner of the third floor of the RC exhibit similar trends. They are geographically distributed according to an ellipsis, showing that the overall dynamic movement is mainly driven by torsion.

\section{Seismic margins assessment}

In this section, the objective is to estimate the seismic margins of the RC specimen based on the experimental data. It is important to note that the concept of structural margin is defined for a given failure criteria. In this study, in accordance with the earthquake engineering practice, two failure criteria are considered; they are expressed in Eqs. (3) and (4) as follows:

$$
\begin{aligned}
& g_{\Delta X}^{k}\left(\Delta X^{k} ; \Delta X_{0}\right)=\max _{\tau \in[0, t]}\left\{\left|\Delta X^{k}(\tau)\right|\right\}-\Delta X_{0} \\
& g_{\Delta f}^{i}\left(f^{i} ; f_{R E F}^{i} ; s_{0}\right)=\left(100 \times \frac{f_{R E F}^{i}-f^{i}}{f_{R E F}^{i}}\right)-s_{0}
\end{aligned}
$$

where $g_{\Delta X}^{k}$ stands for a failure criterion expressed in terms of maximum inter-story drift $\Delta X^{k}$ computed at point $k . g_{\Delta f}^{i}$ is a failure criterion expressed in terms of the ith eigenfrequency shift, $f_{R E F}^{i}$ is the $i$ th initial eigenfrequency identified from the white noise tests, $f^{i}$ is the $i$ th eigenfrequency accounting for damage, $\Delta X_{0}$ and $s_{0}$ are two thresholds that have to be chosen. It is worth noting that both failure criteria should be considered since the first one is related to the local structural response of the RC specimen while the second one is related to the overall dynamic response. Both definitions are meaningful when carrying out seismic margin assessment and therefore, should be considered in order to assess seismic margins; the first one, expressed in terms of inter-story drift, being frequently used in performance-based seismic analyses of RC building, the second one being relevant to determine the impact of structural degradation on floor response spectra. The seismic margin $M_{g}$ can be defined as the lowest ratio $\lambda^{i}$ between the maximum of the PGAs measured in each horizontal direction and the PGA of the design input signal, for which the failure criterion is reached. The loading factor $\lambda^{i}$ is defined as follows:

$\lambda^{i}=\frac{P G A^{i}}{P G A^{\text {Design }}}$

where $P G A^{\text {Design }}$ stands for the PGA of the design seismic signal (equal to $0.2 \mathrm{~g}$ ), while $P G A^{i}$ is the maximum of the PGAs measured in both horizontal directions. According to this definition and considering a generic failure criterion $g, M_{g}$ can be expressed as follows:

$M_{g}=\operatorname{argmin}_{\lambda_{i}}\left\{\lambda_{i} \mid g>0\right\}$

Due to the fact that the RC specimen exhibited the highest structural response at point $D$ located on the third floor when considering the $X$ direction and at point A located on the third floor when considering the $Y$ direction, only these two measurement points were considered for seismic margin estimation. Three different values of the thresholds $\Delta X_{0}$ and $s_{0}$ have been chosen, leading to the definition of three damage levels: limited, controlled and extensive. These denominations are quite usual to qualify the damage state from the knowledge of structural performance indicators. The numerical values are given in Table 7. Regarding the choice of the thresholds, it depends on the type of indicator considered. In the case of the eigenfrequency shift, the thresholds chosen are 


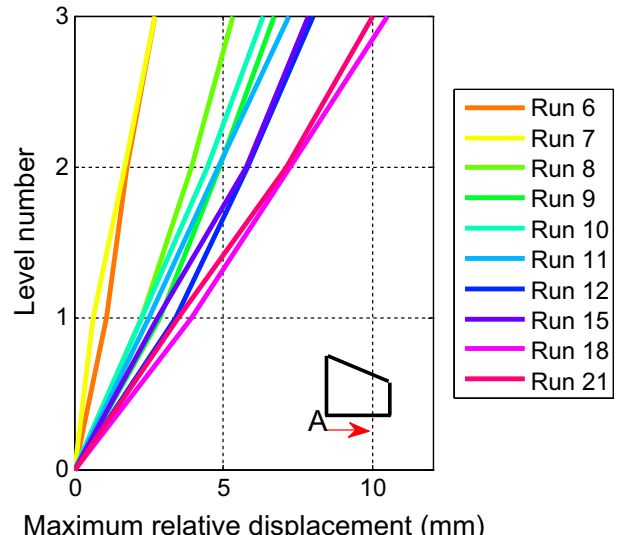

(a) Point A

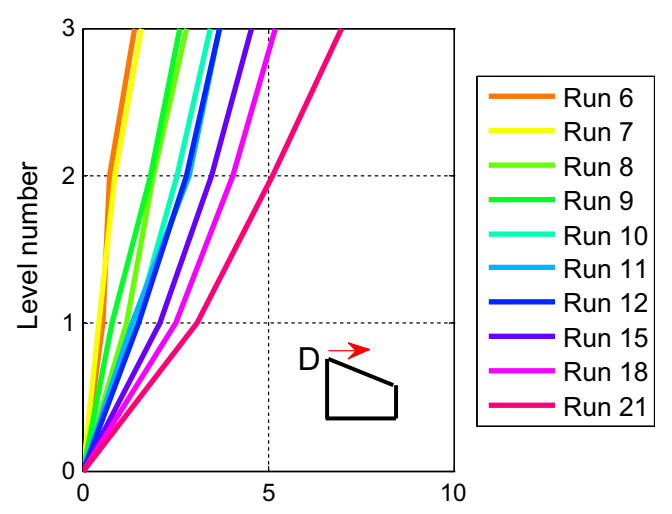

Maximum relative displacement $(\mathrm{mm})$

(b) Point D

Fig. 12. Absolute value of the maximum relative displacements computed in $X$ direction.

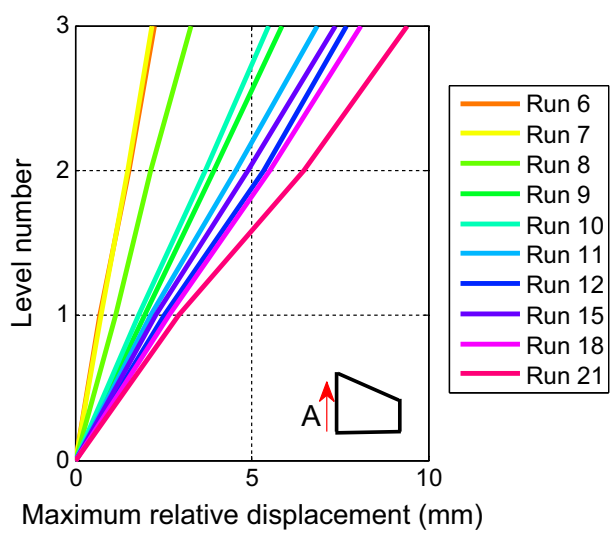

(a) PointA

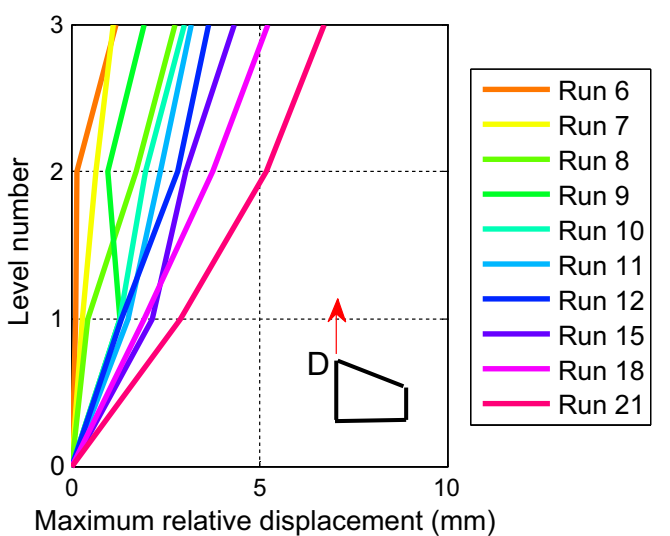

(b) Point D

Fig. 13. Absolute value of the maximum relative displacements computed in $Y$ direction.

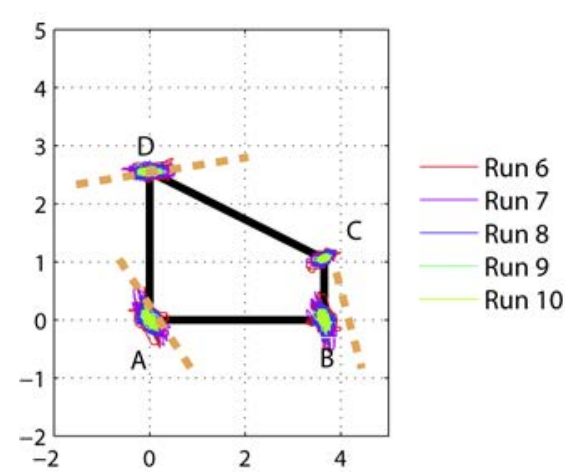

(a) Runs 6 to 10

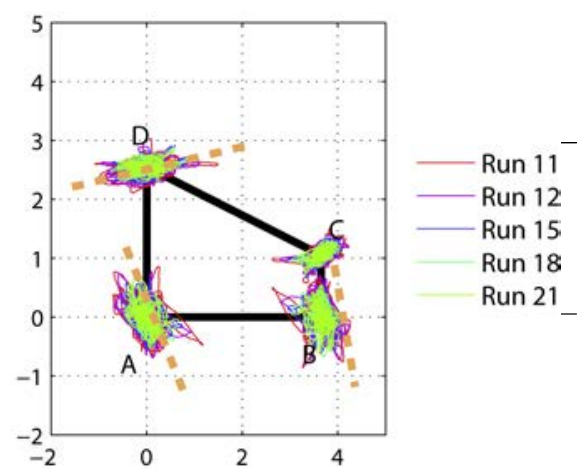

(b) Runs 11 to 21

Fig. 14. Representation of the displacement fields at points A, B, C and D - 3rd floor.

Table 7

Prescribed values of the thresholds for the failure functions ( $h=$ story height equal to $1200 \mathrm{~mm})$.

\begin{tabular}{lll}
\hline Damage level & $\begin{array}{l}\text { Inter-story drift } \\
\text { threshold } \Delta X_{0}(\mathrm{~mm})\end{array}$ & $\begin{array}{l}\text { Eigenfrequency shift } \\
\text { threshold } s_{0}(\%)\end{array}$ \\
\hline Limited & $\frac{h}{400}=3$ & 15 \\
Controlled & $\frac{h}{200}=6$ & 30 \\
Extended & $\frac{h}{100}=12$ & 50 \\
\hline
\end{tabular}

based upon the feedback from experimental campaigns involving wall-based structures [12,27]. In the case of inter-story drifts, the choice of the thresholds was not easy because the structure is strongly irregular. The fact that bending/shear coupling effects are exhibited by the structure makes the use of classical interstory drifts thresholds difficult. However, classical values allowing the definition of drift levels range from $0.25-0.5 \%$ (light damage) to $1-2 \%$ (extensive damage) $[47,48]$. Therefore, rather low values, in 


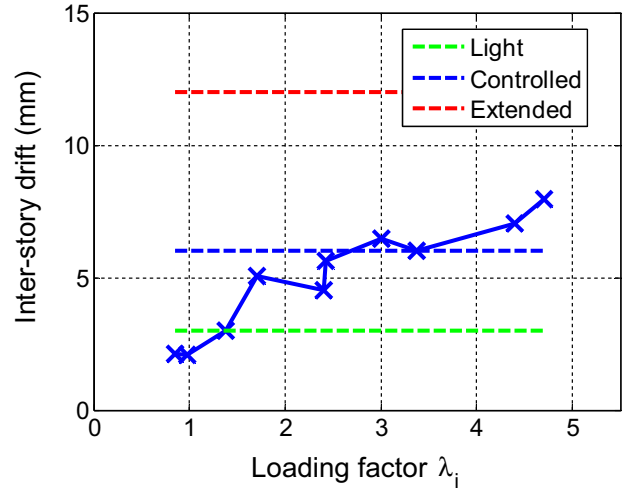

(a) Inter-story drift computed in the $\mathrm{X}$ direction - point D.

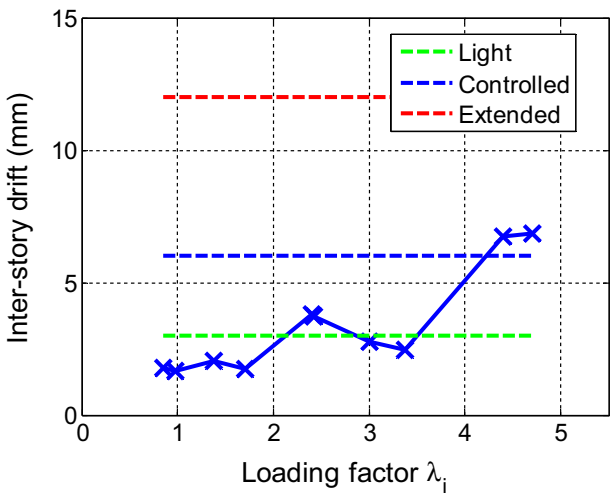

(b) Inter-story drift computed in the $\mathrm{Y}$ direction - point A.

Fig. 15. Absolute value of the maximum inter-story drift computed between the 2 nd and the 3rd floors versus the loading factor.

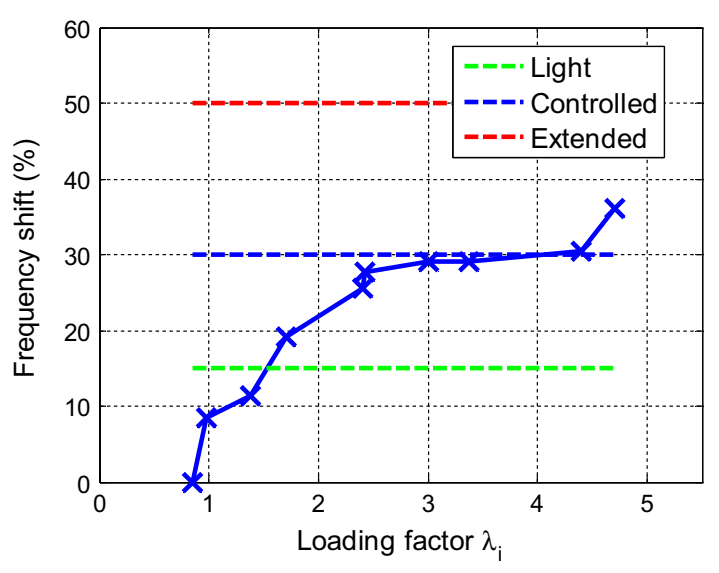

Fig. 16. 1st peak frequency shift versus the loading factor.

accordance with the magnitude of the classical ones, were chosen to go in the way of being conservative and to avoid the overestimation of seismic margins.

The results are shown in Figs. 15 and 16 in terms of maximum inter-story drift and frequency shift, respectively. Looking at Fig. 15, it is interesting to observe that the inter-story drifts computed at point $\mathrm{D}$ in $X$ direction (see Fig. 15a) provide a more conservative estimation of the seismic margin compared to the seismic margin derived from the inter-story drifts computed at point $\mathrm{A}$ in the $Y$ direction. Indeed, if a limited damage level is allowed, Eq. (6) leads to a seismic margin between 1 and 2 in the case of the inter-story drift computed at point $\mathrm{D}$ in the $X$ direction while it leads to a seismic margin between 2 and 3 in the case of the inter-story drift computed at point $\mathrm{A}$ in the $Y$ direction (see Fig. 15b). In addition, looking at Fig. 16, the variations of the frequency shift versus the loading factor is close to the one shown in Fig. 15a. This observation strengthens the fact that the results at point $\mathrm{A}$ in the $\mathrm{Y}$ direction should not be considered for assessing the seismic margins. If a controlled damage level is allowed, Figs. 15a and 16 show that the seismic margin is between 3 and 4. Lastly, if an extensive damage level is allowed, the seismic margin appears as being higher than 5 since the corresponding failure criterion is never reached. A summary of the seismic margin estimation is given in Table 8 .

\section{Concluding remarks and outlooks}

This paper discusses the results from shaking table tests carried out on a RC specimen within the framework of the SMART 2008 CEA-EDF-IAEA joint research project. The $1 / 4$ scale RC specimen under study, fulfilling the similitude laws, is part of an electrical building designed according to the French regulations applicable in the nuclear industry. The seismic test sequence was composed of natural low intensity signals and synthetic signals with a PGA reaching $1.0 \mathrm{~g}$. The synthetic input ground motions have been generated from the design response spectrum.

The experimental crack pattern observed at the end of the seismic test sequence revealed that only moderate damage occurred on the RC specimen. The main damaged areas were located close to the geometric singularities, such as the openings or the shear walls/slab connections. According to the European macroseismic scale updated in 1998 (EMS98) [37], a grade between 2 and 3 would correspond to the observations reported in this paper. Although the collapse of the RC model was not achieved, it is expected that with the increase of the seismic amplitude, the damage concentrates and continues to propagate at the geometric singularities. An experimental modal identification technique was used in order to control the initial conditions and the degraded ones after the seismic sequence of the RC specimen. In particular, this analysis led to an accurate knowledge of the first eigenfrequencies, modal damping ratios and mode shapes. These results pointed out that the structure is prone to manifest a strong coupling between shear and torsional effects, if subjected to seismic loadings.

Table 8

Estimated seismic margins for various failure criteria.

\begin{tabular}{|c|c|c|c|c|}
\hline Failure criterion & & Limited damage & Controlled damage & Extended damage \\
\hline \multirow[t]{2}{*}{ Inter-story drift } & Point D - direction $X$ & $1-2$ & $3-4$ & $>5$ \\
\hline & Point A - direction $Y$ & $2-3$ & $4-5$ & $>5$ \\
\hline Eigenfrequency shift & 1st eigenfrequency & $1-2$ & $3-4$ & $>5$ \\
\hline
\end{tabular}


The overall structural responses monitored during the experimental test sequences confirmed not only the assumed behavior based on the results from the modal identification analysis, but also the fact that an increasing damage occurred. Acceleration floor response spectra were computed for $5 \%$ damping at the most excited point for both horizontal directions. These results revealed that with the increase of the seismic amplitude, the first two peak frequencies shift to lower frequencies. This observation indicates that the RC specimen exhibited a stiffness reduction, leading to a frequency shift almost equal to $30 \%$ of the initial first peak frequency. The maximum relative displacement responses appeared as being spatially distributed in a linear way. This is quite classical when considering wall-based structures with high steel reinforcing ratios. The comparisons between the displacement responses in $X$ and $Y$ directions lead to conclusions regarding the preponderance of torsional effects, not only for low amplitude seismic loadings, but also for high amplitude ones. Qualitative graphical representation corroborates these observations.

The last part of this paper is dedicated to a seismic margins assessment. Two failure criteria were considered, one expressed in terms of first peak frequency shift and another expressed in terms of inter-story drift. It turned out that if a limited damage level is allowed, the RC specimen exhibits a seismic margin between 1 and 2; if a controlled damage level is allowed, the seismic margin is between 3 and 4, and if an extended damage level is allowed, the seismic margin is higher than 5 . It is worth noting that both failure criteria led to the same seismic margin estimations. Taking into account the results from the shaking table tests that fed the seismic margin assessment, it clearly appears that the RC specimen, designed according to French current engineering rules applicable in the nuclear industry, is robust against high amplitude seismic loads. This high value of robustness comes from the fact that the nuclear industry acceptance criteria are much more severe than those of the conventional building industry. In particular, as opposed to conventional building industry practice, behavior factors are not taken into account by the nuclear industry. According to the Eurocode 8 [49], a typical behavior factor for shear wall structures would be around 3. In this regard, the SMART experimental outputs provide evidence that the very limited energy absorption factors presented by the IAEA in its Safety Report on Seismic Evaluation of Existing NPPs (IAEA Safety Report 28, Vienna, 2003) [50] are quite reasonable, even prudent; for shear walls, the IAEA proposes an energy absorption factor in the range 1.50-1.75. Nevertheless, even if no large concrete damage was detected in the low range of seismic level applied to the SMART mock-up, there is evidence in terms of floor response spectra results that non-linear phenomena appear even for lower PGA values, similarly to that observed in [51]. This observation can be questionable for the conventional practice of computing floor response spectra on the basis of an undamaged structural model. It is believed that such an experimental program produces a useful set of data available for improving the computational model and methodologies for the engineering needs; that is the aim of launching the associated SMART benchmark in 2008.

Despite the fact that the RC specimen exhibited a satisfactory behavior under seismic loadings, presenting substantial or moderate damages, one should recognize that the seismic scenario considered is not intrinsically realistic due to the fact that synthetic input ground motions adopted, generated from the design spectrum, were not related to a seismological scenario. In addition, although the proportionality of the seismic runs allowed for the possibility of carrying out a seismic margin assessment, it also led to a progressive introduction or propagation of damages. As the main perspective of the SMART 2008 joint project, a new experimental campaign named SMART 2013 has been launched in which a more realistic seismic scenario is considered. In particular, the effects of a high amplitude main shock, with a frequency content compatible with the first eigenfrequencies of the RC specimen, followed by an after-shock have been investigated. The results will be presented and discussed in a subsequent paper and should confirm the robustness of the RC specimen against such an aggressive seismic scenario.

\section{Acknowledgements}

The authors would like to thank all the participants to the SMART 2008 project and the associated international benchmark for the huge work carried out, namely: R. Crambuer, S. JusterLermitte, A. Saudy, A. Awad, M. Elgohary, F. Maillet, N. Brännberg, H. Ekman, G. Lebon, F. Ragueneau, R. Desmorat, C. Giry, J. Mazars, P. Pegon, A. Yakut, I. Kazaz, B. Thunell, J. Moore, Y. Mondet, A. Klein, U. Burmann, I.K. Choi, D. Hahm, A. Andonov, M. Kostov, K. Apostolov, D. Stefanov, K. Hibino, T. Takada, M.G. Mulas, M. Domaneschi, G.M. Atanasiu, S. Crijanovschi, J.M. Vezin, A. Wahid. CEA and EDF are also gratefully acknowledged for material and financial support. The work reported in this paper has been also supported by the SEISM Institute (http://www.institut-seism.fr).

\section{References}

[1] Červenka V. Inelastic finite element analysis of reinforced concrete panels under in-plane loads [Doctoral dissertation]. University of Colorado; 1979.

[2] Paulay T. Some aspects of shear wall design. Bull N Z Soc Earthq Eng 1972;5(3).

[3] Alexander CM, Heidebrecht AC, Tso WK. Cyclic load tests on shear wall panels. In: Proceedings of the fifth world conference on earthquake engineering, Rome; 1973. p. 1116-9.

[4] Cardenas AE, Russell HG, Corley WG. Strength of low-rise structural walls. ACI Special Publication 63; 1980

[5] Paulay T, Priestley MJN, Synge AJ. Ductility in earthquake resisting squat shear walls. ACI J Proc 1982;79(4).

[6] Hidalgo PA, Ledezma CA, Jordan RM. Seismic behavior of squat reinforced concrete shear walls. Earthq Spectra 2002;18(2):287-308.

[7] Simeonov B. Experimental investigation of the strength, stiffness and ductility of RC structural walls. In: World conference on earthquake engineering, vol. 6; 1998. p. 387-94.

[8] Endebrock EG, Dove RC, Dunwoody WE. Analysis and tests on small-scale shear walls. FY-82 final report (No. NUREG/CR-4274; LA-10443-MS). Los Alamos National Lab., NM, USA; 1985.

[9] Wiradinata S. Behaviour of squat walls subjected to load reversals [Doctora dissertation]. Department of Civil Engineering, University of Toronto; 1985

[10] Dove RC, Bennett JG, Farrar C, Anderson CA. Seismic category I structures program: final report, FY 1983-84 (No. NUREG/CR-4924; LA-11013-MS). Los Alamos National Lab., NM, USA; 1987.

[11] Lefas ID, Kotsovos MD, Ambraseys NN. Behavior of reinforced concrete structural walls: strength, deformation characteristics, and failure mechanism. ACI Struct J 1990;87(1).

[12] Pegon P, Magonette G, Molina FJ, Verzeletti G, Dyngeland T, Negro P, et al. Programme SAFE: Rapport du test T5. Technical note $\mathrm{n}^{\circ}$ I.98.66. EC Joint Research Center, I-21020 Ispra, Italy; 1998.

[13] Parulekar YM, Reddy GR, Vaze KK, Pegon P, Wenzel H. Simulation of reinforced concrete short shear wall subjected to cyclic loading. Nucl Eng Des 2014; 270:344-50.

[14] Barda F, Hanson JM, Corley WG. Shear strength of low-rise walls with boundary elements. ACI Special Publication 53; 1977.

[15] Farrar CR, Bennett JG, Dunwoody WE, Baker WE. Static load cycle testing of a low-aspect-ratio six-inch wall TRG-type structure TRG-4-6 (1.0, 0.25) (No. NUREG/CR-5222; LA-11422-MS). Nuclear Regulatory Commission, Washington, DC, USA. Div. of Engineering; Los Alamos National Lab., NM, USA; 1989.

[16] Farrar CR, Bennett JG, Dunwoody WE, Baker WE. Low-aspect-ratio four-inch wall, TRG-type structure; 1990.

[17] Farrar CR, Bennett JG, Dunwoody WE, Baker WE. Static load cycle testing of a very low-aspect-ratio six-inch wall TRG-type structure TRG-6-6 $(0.27,0.50)$ (No. NUREG/CR-5533; LA-11796-MS). Nuclear Regulatory Commission, Washington, DC, USA. Div. of Engineering; Los Alamos National Lab., NM, USA; 1990.

[18] Farrar CR, Baker WE, Dove RC. Static and simulated seismic testing of the TRG 7 through-16 shear wall structures (No. NUREG/CR-5660; LA-11992-MS). Nuclear Regulatory Commission, Washington, DC, USA. Div. of Engineering; Los Alamos National Lab., NM, USA; 1991

[19] Inada Y. Relationship between force and displacement in RC structures for nuclear reactors [Doctoral dissertation, PhD thesis]. Univ. of Tokyo; 1986.

[20] Shiga T, Shibata A, Takahashi J. Experimental study on dynamic properties of reinforced concrete shear walls. In: Proceedings of the 5th world conference 
on earthquake engineering. International Association for Earthquake Engineering, Rome; 1973.

[21] Ogata K, Kabeyasawa T. Experimental study on the hysteretic behavior of reinforced concrete shear walls under the loading of different moment-toshear ratios. Trans Jpn Concr Inst 1984;6:274-83.

[22] Benjamin JR, Williams HA. Reinforced concrete shear wall assemblies. Trans Am Soc Civil Eng 1961;126(2):114-45.

[23] Umemura H, Aoyama H, Ito M, Hosokawa Y. Aseismic characteristics of RC box and cylinder walls. In: Proceedings of the sixth world conference on earthquake engineering, New Delhi, India; 1976. p. 3144-9.

[24] Bertero VV. The response of shear walls subjected to dynamic loads [Doctora dissertation]. Massachusetts Institute of Technology; 1957.

[25] Antebi J. Model analysis of the response of shear walls to dynamic loads [Doctoral dissertation]. Massachusetts Institute of Technology, Department of Civil and Sanitary Engineering; 1961.

[26] Gergely P. Seismic fragility of reinforced concrete structures and components for application to nuclear facilities. Division of Engineering Technology, Office of Nuclear Regulatory Research, US Nuclear Regulatory Commission; 1985.

[27] Ile N, Plumier C, Reynouard J. Test program on U-shaped walls leading to model validation and implication to design. In: Proceedings of the 12th European conference on earthquake engineering; 2002.

[28] Torita H, Matsumoto R, Kitada Y, Kusama K, Nishikawa T. Shaking table test of Rc box-type shear wall in multi-axes loading. In: 13th world conference on earthquake engineering. August 1-6, 2004. Vancouver, B.C., Canada.

[29] http://www-tamaris.cea.fr/.

[30] Sonin AA. The physical basis of dimensional analysis. Cambridge (MA): Department of Mechanical Engineering, MIT; 2001.

[31] Carvalho EC. Seismic testing of structures. Earthquake engineering-invited papers: proceedings of the eleventh European conference, Paris, France, 6-11 September 1998, vol. 2. CRC Press; 1999. p. 53.

[32] Rapport DES. Proposition de modification de la règle fondamentale de sûreté 1.2. $\mathrm{c}$ relative à la détermination des mouvements sismiques à prendre en compte pour la sûreté des tranches nucléaires comportant un réacteur à eau sous pression, applicable à l'ensemble des installations nucléaires de base. Institut de Protection et de Sûreté Nucléaire; 1998.

[33] Gupta O, Lacoste AC. Prise en compte du risque sismique à la conception des ouvrages de génie civil d'installations nucléaire de base à l'exception des stockages à long terme des déchets radioactifs. Guide de l'Autorité de Sureté Nucléaire. ASN/GUIDE/2/01. Autorité de Sureté Nucléaire; 2006.

[34] Pedron C. Generation and characterization of synthetic signals: preliminary observations and developments. DEN technical report, SEMT/EMSI/RT/98-022/A 1998.
[35] Chaudat T, Lermitte S, Vassic S, Poupin S, Garnier C, Mahe M, et al. SMART 2008 test report. DEN technical report. DEN/DANS/DM2S/SEMT/EMSI/RT/10-007/C; 2010. <http://smart2013.eu/images/docs/smart2008/report/RT_Essai_2008/ RT10007C.pdf>

[36] ISO, P. 6892-1: 2010. Metallic materials - tensile testing - Part, 1, 6892-1; 2010.

[37] Grunthal G. European Macroseismic scale EMS-98. Cahier du Centre Européen de Géodynamique et de Séismologie, vol. 15; 1998.

[38] Ewins DJ. Modal testing: theory and practice, vol. 79. Letchworth: Research Studies Press; 1984.

[39] Heylen W, Sas P. Modal analysis theory and testing. Katholieke Universteit Leuven, Departement Werktuigkunde; 2006.

[40] Cauberghe B. Applied frequency-domain system identification in the field of experimental and operational modal analysis. VUB, Brussel: Praca doktorska; 2004.

[41] Balmes E. New results on the identification of normal modes from experimental complex modes. Mech Syst Signal Process 1997;11(2):229-43.

[42] Richard B, Martinelli P, Voldoire F, Chaudat T, Abouri S, Bonfils N. SMART 2008: overview, synthesis and lessons learnt from the International Benchmark. Eng Struct 2015 [submitted for publication].

[43] Corus M. Experimental modal analyses of the SMART 2008 RC specimen before and after being subjected to seismic loadings. EDF technical report. H-T612009-00261-FR; 2009 [in French].

[44] Martinelli P, Filippou FC. Simulation of the shaking table test of a seven-story shear wall building. Earthq Eng Struct Dynam 2009;38(5):587-607.

[45] Kapur KK, Shao LC. Generation of seismic floor response spectra for equipment design. In: Structural design of nuclear plant facilities. ASCE; 1973. p. 29-71.

[46] Lucchini A, Mollaioli F, Bazzurro P. Floor response spectra for bare and infilled reinforced concrete frames. J Earthq Eng 2014;18(7):1060-82.

[47] Council BSS. Prestandard and commentary for the seismic rehabilitation of buildings, FEMA-356. Federal Emergency Management Agency, Washington, DC; 2000.

[48] Ghobarah A. On drift limits associated with different damage levels. In: International workshop on performance-based seismic design, vol. 28. Department of Civil Engineering, McMaster University, June 2004.

[49] Comité Européen de Normalisation. Eurocode 8 - design of structures for earthquake resistance - Part 1: General rules, seismic actions and rules for buildings. European Standard NF EN, 1; 1998.

[50] International Atomic Energy Agency. Seismic evaluation of existing nuclear power plants, safety reports series, no. 28; 2003.

[51] Labbé P, Altinyollar A. Conclusions of an IAEA-JRC research project on the safety significance of near-field seismic motions. Nucl Eng Des 2011;241 (5):1842-56. 